DOI 10.15826/B978-5-7996-2935-9.43

ВЕЙВЛЕТ-АНАЛИЗ 2D-РАСПРЕДЕЛЕНИЙ АСТЕРОИДОВ ГЛАВНОГО ПОЯСА И ЗВЕЗДНОГО НАСЕЛЕНИЯ ГАЛАКТИКИ

Р. В. Балуев ${ }^{1,2}$, Е. И. Родионов ${ }^{1}$, В. Ш. Шайдулин ${ }^{1}$, А. В. Веселова ${ }^{1}$

${ }^{1}$ Санкт-Петербургский государственный университет, ${ }^{2}$ Главная (Пулковская) астрономическая обсерватория РАН

В работе представляется программный комплекс обработки двумерных функций распределения статистических выборок на основе нового самосогласованного метода вейвлет-анализа.

\title{
WAVELET ANALYSIS OF 2D DISTRIBUTIONS IN THE MAIN BELT AND MILKY WAY POPULATIONS
}

R. V. Baluev ${ }^{1,2}$, E. I. Rodionov ${ }^{1}$, V. Sh. Shaidulin ${ }^{1}$, A. V. Veselova ${ }^{1}$

${ }^{1}$ Saint Petersburg State University, ${ }^{2}$ Central Astronomical Observatory at Pulkovo of $R A S$

We present a self-consistent mathematical and algorithmic framework to perform the continuous wavelet analysis of two-dimensional statistical distributions.

Производится поиск статистически значимых структур двумерного распределения, связанных с поведением сглаженного лапласиана плотности вероятности. Эти структуры могут включать локальные уплотнения (кластеры объектов) или разрежения (провалы в распределении). Алгоритм строит наиболее экономную модель функции плотности, содержащую только значимые структуры. Метод основан на новых оптимальных в данной задаче вейвлетах и оптимальных восстанавливающих ядрах, а также использует ранее неизвестную аналитическую аппроксимацию для значимости извлекаемых структур. Метод апробирован на статистических распределениях различных астрономических объектов: астероидов Главного пояса (орбитальные параметры $a, e, \sin i$ ) и звездного населения Галактики по данным GAIA DR2 (компоненты скорости $U, V, W$ ). Для этих ансамблей проведен поиск всех статистически значимых

(c) Балуев Р. В., Родионов Е. И., Шайдулин В. Ш., Веселова А. В., 2020 
семейств по каждой из трех возможных пар параметров, а затем осуществлено их взаимоотождествление в соответствующем трехмерном пространстве.

Работа выполнена при поддержке гранта РФФИ 17-02-00542 А. 